\title{
Concorrência e estratégias de precificação no sistema agroindustrial do leite
}

\author{
Paulo Furquim de Azevedo ${ }^{1}$ \\ Ricardo Batista Politi
}

Resumo: O objetivo deste trabalho é caracterizar o padrão de concorrência no mercado de leite fluido (longa vida e pasteurizado), a partir de evidências sobre os movimentos de preços no varejo e do comportamento das margens de mercado. Utilizou-se o modelo originalmente proposto por Houck (1977), acrescido das observações feitas por Carman e Sexton (2005). Essa abordagem separa as variáveis explicativas entre aumentos e diminuições de preços pagos ao produtor e permite comparar a defasagem entre esses dois movimentos e estudar a estratégia de preços dos agentes a partir das margens dos intermediários. O período analisado foi de dezembro de 1999 a dezembro de 2005 com dados de preços ao consumidor da Fundação Instituto de Pesquisas Econômicas (Fipe) e dados de preços ao produtor do Centro de Estudos Avançados em Economia Aplicada (Cepea), da Universidade de São Paulo (USP). Identificou-se que o padrão de concorrência do leite longa vida é bastante distinto do encontrado para o leite pasteurizado. Enquanto para o leite longa vida o padrão de concorrência é mais próximo do modelo competitivo, para o leite pasteurizado o padrão encontrado foi de menor concorrência e

\footnotetext{
* Os autores agradecem a FIPE-USP e ao CEPEA-USP, pela disponibilidade de dados, bem como aos comentários de Mario Antonio Margarido e de Alexandre Lahoz Mendonca de Barros. Os erros remanescentes são de única responsabilidade dos autores. ${ }^{1}$ Prof. Dr. da Fundação Getúlio Vargas - Escola de Economia de São Paulo / EESP-FGV Doutorando em Economia - EESP/FGV - Escola de Economia de São Paulo / EESP-FGV
} 
liquidez. O vertiginoso crescimento das vendas de leite longa vida, absorvendo grande parte do mercado antes abastecido pelo leite pasteurizado, trouxe maior concorrência nos segmentos de indústria e distribuição, bem como maior velocidade de transmissão de preços ao longo da cadeia produtiva. Entretanto, a precificação com markup com percentual fixo, observada no leite longa vida, indica que indústria e distribuição gozam de algum poder de mercado e que variações absolutas de custo da matéria-prima são repassadas em maior magnitude ao consumidor final.

Palavras-chave: concorrência, transmissão de preços, leite.

Abstract: This article aims to evaluate the degree of competition in the dairy industry, in the relevant markets of Ultra High Temperature (UHT) milk and pasteurized milk, by means of price transmission and marketing margin behavior. The empirical analysis is based on the model formerly proposed by Houck (1977) and latter detailed by Carman and Sexton (2005).This model analyzes separately the effects of input price increases and reductions on consumer prices, allowing for estimations of price transmission and margin behavior. Cepea-USP and Fipe provide, respectively, weekly input prices and consumer prices, both for the period of December 1999 to December 2005. As a major result, the degree of competition in the UHT relevant market was found to be robustly different from the pasteurized milk market. Whereas in the first price transmission corroborates the hypothesis of competitive market, in the pasteurized milk market there is evidence of imperfections both in price transmission and margin behavior. The outstanding increase of UHT milk consumption has fostered competition and liquidity in the dairy industry and milk distribution, allowing for faster price transmission throughout the production chain. Nevertheless fixed markup pricing found in the UHT relevant market shows that dairy industry and milk distribution have some degree of market power so as nominal changes in input prices are passed through consumers in a larger magnitude.

Key words: competition, price transmission, dairy industry.

JEL: L11, Q13 


\section{Introdução}

A introdução do leite longa vida transformou a indústria de laticínios no Brasil. Em aproximadamente 15 anos, entre o final da década de 1980 e 2004, o leite longa vida conquistou cerca de $80 \%$ do mercado de leite fluido brasileiro. Esse crescimento explosivo da participação do leite longa vida na oferta de leite fluido alterou as relações de concorrência entre pontos de venda e entre laticínios, com reflexos nas margens dessas empresas e no modo que as alterações de preços fluem pela cadeia produtiva. Por conta dessa cadeia de causalidade, o crescimento do leite longa vida afeta os preços recebidos pelos produtores de leite e sua distribuição geográfica.

A contribuição desta pesquisa está na aplicação de um teste empírico para caracterizar a estrutura de concorrência nos mercados de leite longa vida e pasteurizado, por meio de uma análise de transmissão de preços ao longo da cadeia produtiva. Os preços ao varejo são referentes à cidade de São Paulo, correspondendo a uma produção originária do estado de São Paulo, no caso do leite pasteurizado, e nacional, no caso do leite longa vida.

O teste segue a especificação proposta por Houck (1977), que, ao contrário dos modelos tradicionais de transmissão de preços, separa as variáveis explicativas em aumento e diminuição de preços ao produtor. Inúmeros autores têm utilizado esse teste de transmissão de preços para o mercado de leite (Aguiar e Santana, 2002; Capps e Sherwell, 2005; Carman e Sexton, 2005; Frigon e Doyon e Romain, 1999). Por meio deste teste, é possível levantar informações a respeito da simetria da transmissão de preço do produtor ao consumidor final, bem como apontar evidências sobre o padrão de concorrência e estratégias de preços aplicadas na cadeia (Carman; Sexton, 2005).

$\mathrm{O}$ artigo divide-se em cinco seções, incluindo a introdução. A segunda seção apresenta algumas características do Sistema Agroindustrial do Leite (SAL) necessárias à compreensão das diferenças técnicas e de padrão de concorrência entre os mercados de leite longa vida e pasteurizado. A terceira seção apresenta a metodologia seguida do tratamento dos dados, e a quarta seção traz uma síntese dos resultados da análise das estratégias de precificação 
nos dois mercados. A última seção desenvolve algumas implicações dos resultados para análises setoriais e de políticas públicas voltadas à produção leiteira, além de apresentar limitações da pesquisa e sugestões para trabalhos futuros.

\section{Características técnicas e padrão de concorrência nos merca- dos de leite longa vida e pasteurizado}

Esta seção destaca algumas características do Sistema Agroindustrial do Leite (SAL), particularmente na produção de leite longa vida e pasteurizado. A motivação principal é entender de que modo as características técnicas da produção desses dois tipos de leite fluido afetam a concorrência em cada um dos mercados. Esta é a base descritiva que serve como sustentação para o teste empírico sobre as estratégias de precificação de laticínios e as implicações do aumento de participação do leite longa vida na oferta de leite fluido. Para tanto, a seção aborda superficialmente alguns aspectos de estrutura de mercado e, posteriormente, algumas características técnicas do produto e suas implicações.

\subsection{Características gerais dos mercados de leite fluido}

Os três segmentos principais que compõem o SAL apresentam estruturas de mercado bastante distintas. Em relação à produção, o número de participantes, ainda que em declínio, são centenas de milhares (Martins, 2004). Mesmo considerando que há diferentes mercados regionais, cuja extensão foi alargada pela coleta de leite a granel, trata-se de um mercado bastante pulverizado, sem participantes com condições de afetar os preços. Na indústria, essa proporção cai, mas o número de laticínios distribuídos pelo país ainda é expressivo. Segundo dados do Ministério da Agricultura, em 2005, existiam cerca de 1.100 pequenos laticínios no País e mais algumas centenas que podem ser caracterizados como de médio porte (Neves; Consoli, 2005). Se considerados apenas aqueles com distribuição nacional ou presença regional significativa, o número não passa de algumas dezenas (Barros et al., 2001). É freqüente no SAL a integração vertical para frente por parte 
de produtores de leite, na forma de cooperativas, as quais somavam cerca de 290, em 2005, com as maiores concentradas em Minas Gerais e São Paulo (Neves; Consoli, 2005). A participação das cooperativas no Brasil é, entretanto, inferior à verificada em diversos outros países, notadamente na União Européia e nos Estados Unidos (Azevedo et al., 2004). Das 15 maiores indústrias processadoras em 2004, apenas três eram controladas por cooperativas (Embrapa, 2005).

Apesar da crescente concentração nos últimos 20 anos, o varejo ainda é bastante pulverizado no País, com participação de supermercados, padarias e pequenos armazéns (Barros et al., 2004). Em 2005, havia cerca de 72 mil pontos de venda de varejo e 52 mil padarias espalhadas pelo Brasil (Neves e Consoli, 2005), que atendiam mercados de pequena extensão geográfica, delimitados pelos custos de deslocamento dos consumidores. Embora haja milhares de pontos de venda, a estrutura de mercado de distribuição tende a ser relativamente concentrada em cada um desses mercados, cuja área de atendimento freqüentemente é circunscrita ao bairro.

Segundo dados da POF/Fipe ${ }^{3}$, o supermercado é o principal local para compra de leite e seus derivados, exceção feita ao caso do leite pasteurizado tipo B e C, para o qual é o segundo colocado, perdendo em participação para padarias e bares (Margarido; Martins, 2005). A explicação para a concentração da distribuição de leite pasteurizado nas padarias deve-se à maior freqüência de compras, o que torna mais relevante o custo de transporte e de tempo incorrido pelos consumidores. Por esse motivo, estes tendem a privilegiar os canais de distribuições mais próximos.

A exemplo dos maiores produtores mundiais, no Brasil, quase a totalidade do leite fluido produzido é destinado ao consumo interno. As importações de leite longa vida são pouco expressivas, representando cerca de $3 \%$ do volume total das compras de leite e derivados entre 2004 e 2005, enquanto as de leite pasteurizado são inexistentes (Embrapa, 2005). Essas importações vêm da Argentina e do Uruguai, normalmente em períodos de câmbio valorizado, que torna o preço do produto importado mais atrativo (Jank; Galan, 1998). Dada a pequena

${ }_{3}^{3}$ Pesquisa de Orçamentos Familiares (POF). Fundação Instituto de Pesquisas Econômicas (FIPE). São Paulo, 1999. 
participação do leite longa vida no volume exportado e importado, conforme exibido na Tabela 1, pode-se afirmar que o preço desse produto é definido pelo mercado interno.

Tabela 1 - Produção, importação e exportação de leite longa vida (em milhares de litros)

\begin{tabular}{c|c|c|c}
\hline Ano & Produção Interna & Importação & Exportação \\
\hline 1990 & 187 & 0 & 0 \\
1991 & 204 & 0 & 0 \\
1992 & 355 & 0 & 0 \\
1993 & 449 & 7 & 0 \\
1994 & 713 & 17 & 0 \\
1995 & 1.014 & 36 & 0 \\
1996 & 1.614 & 86 & 0 \\
1997 & 2.330 & 120 & 0 \\
1998 & 2.965 & 135 & 0 \\
1999 & 3.300 & 125 & 0 \\
2000 & 3.504 & 96 & 0 \\
2001 & 3.912 & 39 & 0 \\
2002 & 4.193 & 27 & 0 \\
2003 & 4.225 & 2 & 0 \\
2004 & 4.402 & 1 & 0 \\
\hline
\end{tabular}

Fonte: EMBRAPA, 2005

\subsection{Características técnicas e mercados relevantes}

A análise de concorrência pressupõe uma adequada delimitação do mercado relevante em que se dá a competição entre as empresas, particularmente as suas fronteiras geográficas e as características dos produtos que o compõem. No caso do leite fluido, a delimitação dos mercados decorre, sobretudo, das características técnicas de cada tipo de leite.

O leite pasteurizado e o leite longa vida são leites fluidos produzidos pela indústria a partir do leite cru, recolhido e refrigerado na propriedade rural. Os tipos de leite são classificados segundo o percentual de proteínas e gordura na matéria-prima e de acordo com a maior ou menor 
presença de microorganismos, como bactérias e células somáticas que deterioram o produto. Com base nesses critérios, o leite tipo A é o de melhor qualidade, o tipo $\mathrm{B}$, de qualidade intermediária e o tipo $\mathrm{C}$, de qualidade inferior (Milkpoint, 2005).

Por meio do processo de ultrapasteurização, o leite cru é submetido a uma temperatura entre 130 e $150{ }^{\circ} \mathrm{C}$ de dois a quatro segundos, sendo, em seguida, resfriado a uma temperatura inferior a $32^{\circ} \mathrm{C}$ e, então, envasado em embalagem cartonada asséptica (Itambé, 2005). Obtém-se, então, o conhecido leite longa vida ou UHT (ultra high temperature). Esse processo elimina todos os microorganismos que por ventura poderiam contaminar ou deteriorar o leite (Alves, 2001), sendo, portanto, um processo especialmente apropriado para a industrialização de leite cru de qualidade inferior, como é o caso do leite tipo C. Por se tratar de um leite esterilizado, o leite longa vida apresenta um prazo de validade para consumo de até 180 dias, podendo ser distribuído nacionalmente sem necessidade de refrigeração (Barros et al, 2001). Em contraposição, seu substituto mais próximo, o leite pasteurizado tipo $\mathrm{C}$, tem prazo de validade de apenas 5 dias, necessitando, ademais, de refrigeração.

Essa distinção é fundamental na delimitação dos mercados relevantes de leite fluido. Em sua dimensão produto, embora os diversos tipos de leite pasteurizado sejam substitutos imperfeitos entre si, visto que atendem a públicos distintos, o grau de substituibilidade é suficientemente grande para agregá-los em um mesmo mercado, notadamente os leites tipo B e $\mathrm{C}$. No que se refere ao leite longa vida, as suas características de armazenagem por longo período e sem necessidade de resfriamento reduzem fortemente a possibilidade de substituição frente ao leite pasteurizado. Ademais, os equipamentos necessários à produção do leite longa vida são distintos daqueles empregados na produção de leite pasteurizado, não havendo, portanto, substituibilidade pelo lado da oferta. Em síntese, tratam-se de mercados relevantes distintos, devendo ser objeto de uma análise em separado.

Por seu maior prazo de validade e independência em relação à cadeia de distribuição a frio, a abrangência geográfica do mercado de leite longa vida é consideravelmente maior que a do leite pasteurizado, 
sendo comumente circunscrita às fronteiras nacionais, dada a pequena participação das importações. O leite pasteurizado, por sua vez, exige elevada freqüência de compras, tornando mais relevante o custo de transporte e de tempo dedicado à compra, o que reduz o raio de cada mercado relevante. Tal característica confere menor liquidez ao mercado de leite pasteurizado, bem como admite que pontos de venda desfrutem de poder de mercado naquela área em que atuam, a depender da distância dos demais pontos de venda.

Por conta das diferenças técnicas que resultam em menor prazo de validade e necessidade de distribuição a frio do leite pasteurizado, há dois importantes efeitos sobre os dois mercados de leite fluido. De um lado, o perfil dos canais de distribuição é bastante distinto, havendo predominância de supermercados, no caso do longa vida, e de padarias, no caso do pasteurizado. De outro, o leite longa vida permitiu a expansão da área de atuação de cada laticínio, o que fez aumentar o número de concorrentes em cada mercado. Por conseguinte, segundo o conceito de localização geográfica, é esperado um padrão de concorrência diferente entre o leite pasteurizado e o leite longa vida.

Apesar de estar disponível no País desde a década de 1970, foi só nos anos 90 que o leite UHT passou a ser predominante no mercado, visto que, até então, predominava o leite pasteurizado embalado em saco plástico, de polietileno (Alves, 2001). A Figura 1 mostra que, após o crescimento vertiginoso na década de 1990, a participação nas vendas do leite longa vida se estabilizaram em torno de $80 \%$ do total de consumo de leite fluido.

Uma vez que o padrão de concorrência no mercado de leite longa vida deve diferir acentuadamente do observado no de leite pasteurizado, o forte crescimento da participação do leite longa vida deve ter efeitos sobre todos os componentes do SAL, particularmente os pecuaristas e consumidores. O leite longa vida aproximou os produtores de leite distantes dos maiores mercados consumidores do País, onde estão as grandes redes varejistas, alterando o padrão de concorrência até então predominante, baseado nas tradicionais bacias leiteiras produtoras que forneciam leite pasteurizado para mercados locais pulverizados em milhares de estabelecimentos, normalmente padarias ou pequeno comércio (Jank; Galan, 1998). 
Figura 1 - Consumo de leite fluido no Brasil por sub-tipo de 1990 a 2005

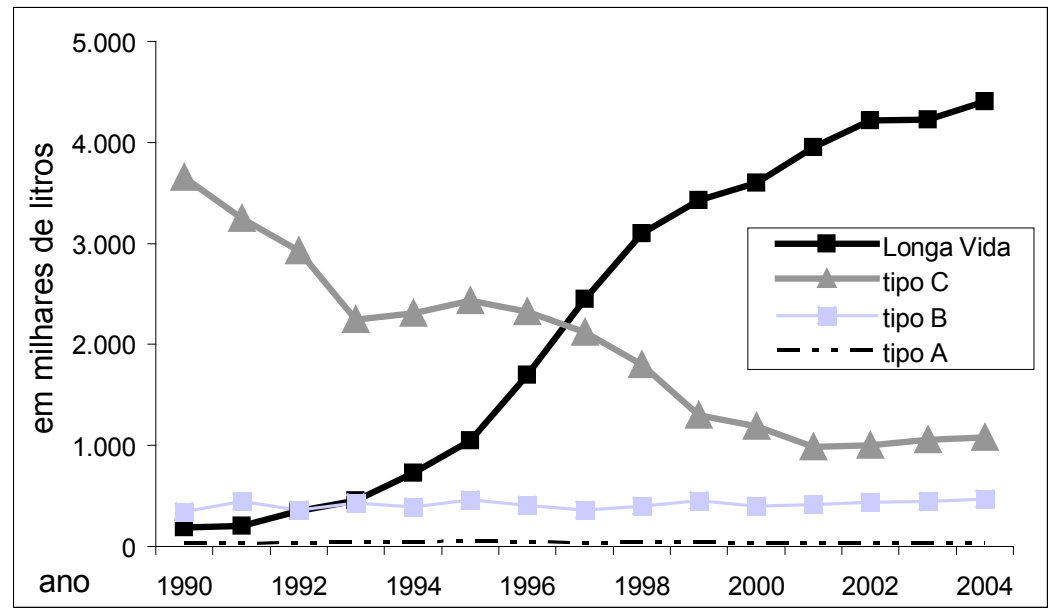

Fonte: EMBRAPA, 2005

\section{Concorrência nos mercados de leite longa vida e pasteurizado: um teste empírico}

A questão central deste artigo é comparar o padrão de concorrência nos mercados de leite longa vida e pasteurizado, o que é feito por meio da comparação entre as estratégias de precificação em cada um desses mercados. Para tanto, nesta seção, é apresentada uma análise empírica da transmissão de preços ao longo das cadeias produtivas de leite longa vida e pasteurizado, com o objetivo de identificar padrões de conduta de precificação, o que, por sua vez, releva as condições de concorrência em cada um dos mercados.

As estratégias de precificação podem ser bastante variadas. $\mathrm{O}$ agente fornecedor poderá empregar uma estratégia simples de markup, por meio de um sobrepreço nominal fixo (por exemplo, R\$ 1,00 por unidade comercializada) ou um sobrepreço relativo sobre o custo total de produção (Carman; Sexton, 2005). A estratégia de precificação poderá seguir modelos mais elaborados, mas o ponto fundamental aqui discutido diz respeito à transmissão dos preços pela cadeia produtiva, particularmente sua velocidade, magnitude e simetria para quedas 
e elevações de preços. Desse modo, esta seção pretende identificar a estrutura de concorrência do mercado a partir do comportamento de preços do produtor ao consumidor final. Essa tarefa é facilitada dado que o leite fluido é um produto homogêneo e sobre o qual não incidem grandes transformações da sua extração na fazenda até atingir o consumidor final. Por isso, é esperada uma grande relação entre o preço pago ao produtor e o preço encontrado pelo consumidor no ponto de venda (Frigon; Doyon; Romain, 1999). Os movimentos de preços da matéria-prima e do produto final, neste caso leite longa vida ou pasteurizado, fornecerão informações importantes a respeito da margem da indústria e varejo, e, portanto, colaborarão na descrição da conduta desses agentes.

Em um mercado perfeitamente competitivo, é esperada uma perfeita transmissão das oscilações de preço, em curto espaço de tempo e na mesma proporção (Frigon; Doyon; Romain, 1999). Nesse caso, diferenças de preços entre os tipos de leite só deveriam refletir diferenças nos custos de produção (Carman; Sexton, 2005).

Na utilização dos dados de preços ao produtor e ao varejo, foi considerado o aspecto geográfico. Este pode refletir o poder de mercado dos agentes intermediários locais, tanto indústria como varejo. A utilização de dados nacionais não permite analisar esses efeitos e, portanto, a utilização de dados regionais é mais recomendável (Capps; Sherwell, 2005). Aguiar e Santana (2002) utilizaram essa mesma abordagem para pesquisar a transmissão de preços de alguns produtos agroindustriais, entre eles o leite em pó.

\section{Metodologia}

A especificação do teste originalmente proposto por Houck (1977) separa as variações no preço pago ao produtor em duas variáveis explicativas; sendo uma variável para acréscimo e outra variável para decréscimo de preço, com as diferenças de preço no varejo, sendo esta a variável dependente (Carman; Sexton, 2005), conforme assinalado a seguir:

$$
P V_{t=} \beta_{0} t+\beta_{1} P_{t}+\beta_{2} P_{t} P_{t}+\beta_{3} c_{t}+e_{t}
$$


Em que:

$\mathrm{PV}_{\mathrm{t}=} \mathrm{P}_{\mathrm{t}}-\mathrm{P}_{0}$ (variações absolutas mensais do preço no varejo em relação ao preço inicial)

$\beta_{0}=$ coeficiente de tendência

$\mathrm{t}=$ tempo (meses)

$\mathrm{PAP}_{\mathrm{t}=} \sum_{t=1}^{T}\left(\mathrm{PP}_{\mathrm{t}}-\mathrm{PP}_{\mathrm{t}-1}\right)$, para $\mathrm{PP}_{\mathrm{t}}>\mathrm{PP}_{\mathrm{t}-1}$, caso contrário igual a zero (acréscimo do preço pago ao produtor em termos absolutos)

$\mathrm{PDP}_{\mathrm{t}=} \sum_{t=1}^{T}\left(\mathrm{PP}_{\mathrm{t}}-\mathrm{PP}_{\mathrm{t}-1}\right)$, para $\mathrm{PP}_{\mathrm{t}}<\mathrm{PP}_{\mathrm{t}-1}$, caso contrário igual a zero (decréscimo do preço pago ao produtor em termos absolutos)

$c_{t}=$ variação do custo de processamento e distribuição

A variável preço varejo $\left(\mathrm{PV}_{\mathrm{t}}\right)$ é construída a partir das variações absolutas mensais do preço no varejo em relação ao preço inicial, ou seja, as variações mensais em termos absolutos acumuladas no decorrer do tempo.

As variáveis de acréscimo ( $\left.\mathrm{PAP}_{\mathrm{t}}\right)$ e de decréscimo $\left(\mathrm{PDP}_{\mathrm{t}}\right)$ do preço pago ao produtor $\left(\mathrm{PP}_{\mathrm{t}}\right.$ ) são obtidas separadamente a partir da somatória das diferenças do aumento (ou da diminuição) do preço de um mês em relação ao mês anterior. Quando houver aumento, só a variável de acréscimo é alterada, quando houver uma diminuição, apenas a variável decréscimo muda. A Tabela 2 serve como exemplo para construção das variáveis descritas. As variáveis em destaque são as utilizadas na regressão.

Uma vantagem desse modelo é que os valores dos coeficientes de acréscimo e decréscimo de preços são diretamente comparáveis, sem qualquer necessidade de transformação, inclusive de sinal algébrico (Houck, 1977). Se os preços no varejo e os preços pagos ao produtor estiverem relacionados, então os coeficientes $\beta_{1}$ e $\beta_{2}$ serão positivos (Carman; Sexton, 2005). Em contrapartida, por sua construção, o modelo proposto por Houck, embora constitua o principal procedimento para teste de assimetria em transmissão de preços na literatura econômica, é reconhecidamente sujeito a problemas de multicolinearidade (No et al., 2004), o que pode tornar os testes inconclusos no caso de não-rejeição da hipótese nula. 
Tabela 2 - Exemplo de como obter as variáveis do modelo

\begin{tabular}{c|ccccc|c|c|c|c|}
\hline \multirow{2}{*}{ data } & \multicolumn{2}{|c|}{ preço } & \multicolumn{2}{c|}{ preço produtor } & \multicolumn{2}{c|}{ preço produtor } & \multicolumn{2}{c|}{ preço varejo } \\
\cline { 2 - 9 } & varejo & produtor & PAP $_{\mathrm{t}}$ & $\mathrm{PDP}_{\mathrm{t}}$ & $\Sigma \mathrm{PAP}_{\mathrm{t}}$ & $\Sigma \mathrm{PDP}_{\mathrm{t}}$ & $\mathrm{PV}$ & $\Delta \mathrm{PV}$ \\
\hline dez/99 & 1,073 & 0,250 & 0 & 0 & 0 & 0 & 0 & 0 \\
jan/00 & 1,027 & 0,280 & 0,030 & 0 & 0,030 & 0 & $(0,046)$ & $(0,046)$ \\
fev/00 & 1,035 & 0,280 & 0 & 0 & 0,030 & 0 & 0,008 & $(0,038)$ \\
mar/00 & 1,065 & 0,280 & 0 & 0 & 0,030 & 0 & 0,029 & $(0,008)$ \\
abr/00 & 1,142 & 0,290 & 0,010 & 0 & 0,040 & 0 & 0,077 & 0,069 \\
mai/00 & 1,197 & 0,310 & 0,020 & 0 & 0,060 & 0 & 0,055 & 0,124 \\
jun/00 & 1,446 & 0,330 & 0,020 & 0 & 0,080 & 0 & 0,249 & 0,373 \\
jul/00 & 1,688 & 0,350 & 0,020 & 0 & 0,100 & 0 & 0,242 & 0,615 \\
ago/00 & 1,707 & 0,370 & 0,020 & 0 & 0,120 & 0 & 0,019 & 0,634 \\
set/00 & 1,415 & 0,380 & 0,010 & 0 & 0,130 & 0 & $(0,292)$ & 0,342 \\
out/00 & 1,164 & 0,350 & 0 & $(0,030)$ & 0,130 & $(0,030)$ & $(0,252)$ & 0,091 \\
nov/00 & 1,154 & 0,310 & 0 & $(0,040)$ & 0,130 & $(0,070)$ & $(0,010)$ & 0,081 \\
dez/00 & 1,152 & 0,290 & 0 & $(0,020)$ & 0,130 & $(0,090)$ & $(0,002)$ & 0,079 \\
\hline
\end{tabular}

Fonte: elaboração própria

Houck assinala que se a constante na equação for diferente de zero, funcionará como um coeficiente de tendência (Houck, 1977). Em sua especificação, Houck não faz qualquer menção a respeito de um índice de custo do mercado, mas Carman e Sexton acrescentam esse índice na estrutura, sendo esta a especificação adotada para o presente trabalho (Carman; Sexton, 2005). Para refletir o custo do varejo, deve ser considerada mãode-obra, energia, custo de armazenamento e embalagem (Heien, 1980).

As informações obtidas a partir do modelo serão analisadas em três aspectos. O primeiro deles está relacionado à simetria de preços. Se o aumento e a diminuição do preço pago ao produtor apresentarem o mesmo poder de influenciar o preço no varejo, então haverá simetria de transmissão. Portanto, a hipótese nula a ser testada será se $\beta_{1}=\beta_{2}$ contra a hipótese alternativa de $\beta_{1}>\beta_{2}$ ou $\beta_{1}<\beta_{2}$; para tal, o teste estatístico t será aplicado (Carman; Sexton, 2005). O caso em que $\beta_{1}>\beta_{2}$ é de especial interesse, uma vez que se a hipótese não for rejeitada, significa que a transmissão de acréscimo de preços do produtor ao varejo é maior que a transmissão de decréscimo, o que não é consistente com a estrutura de mercado de concorrência perfeita (Houck, 1977). 
A segunda situação a ser analisada diz respeito à velocidade de transmissão do aumento e da diminuição de preços do produtor para o varejo. Para isso, serão analisados se os movimentos de acréscimo e decréscimo no varejo apresentam defasagens diferentes, indicando se as alterações de preços da matéria-prima são repassadas em momentos diferentes, dependendo se o movimento for de aumento ou de diminuição do preço. Para os casos de mercados menos competitivos, se espera encontrar uma transmissão mais rápida de aumento de preços da matéria-prima em comparação com a transmissão de queda de preços (Carman; Sexton, 2005). Caso não haja diferença de defasagens entre os coeficientes, não haverá evidência de poder de mercado.

A terceira análise se baseia nos valores assumidos pelos coeficientes de acréscimos e decréscimos. Obtidos a partir das variações absolutas de preços, esses valores fornecem informações a respeito das estratégias de preços da indústria e do varejo (Carman; Sexton, 2005). Essas estratégias colaboram para entender se a estrutura do mercado está mais próxima do modelo concorrencial ou do oligopólio. Assumindo uma curva de demanda linear, o monopólio apresenta uma curva de receita marginal com o dobro da inclinação da demanda do mercado (Shy, 1996). Como representado na Figura 2, a curva de demanda apresenta metade da inclinação da curva de receita marginal, espera-se que a oscilação de preço para o consumidor final seja metade da oscilação do custo marginal do monopolista (Varian, 1999). Assim, a hipótese nula a ser verificada para a existência de monopólio é se $\beta_{1}=\beta_{2}=0,5$ (Carman; Sexton, 2005).

Dessa forma, no monopólio, a magnitude da transmissão de preço deve ser a metade do esperado para concorrência perfeita. No caso de concorrência perfeita, a hipótese nula estabelecida é $\beta_{1}=\beta_{2}=1$ (Carman; Sexton, 2005). Assim, a transmissão de preço seguirá um markup em valor absoluto, no qual o aumento ou a queda de, por exemplo, $\mathrm{R} \$ 0,10$ em custo marginal do produto é repassado no mesmo montante para o consumidor. É importante lembrar que, no modelo de concorrência perfeita, as empresas são tomadoras de preços e fazem o ajuste da quantidade produzida, o que, por sua vez, no agregado, pode alterar o preço de mercado. No teste aqui proposto, supõe-se que os demais componentes de custo, além da matéria-prima (leite cru), são remunerados 
exatamente por seu custo marginal, o que é o resultado de concorrência perfeita. Desse modo, um aumento do preço do insumo, em condições de concorrência perfeita, deve resultar, como resposta imediata dos laticínios, em elevação do preço final no mesmo montante em termos absolutos. Se esse aumento de preços acarretar queda da demanda em um segundo momento, o ajuste de quantidade deve ocorrer na produção leiteira, resultando em arrefecimento do aumento inicial de preços, a depender das elasticidades da demanda e da oferta. Quanto maior a elasticidade da demanda menor o markup praticado na cadeia (Varian, 1999).

Figura 2 - Modelo monopólio

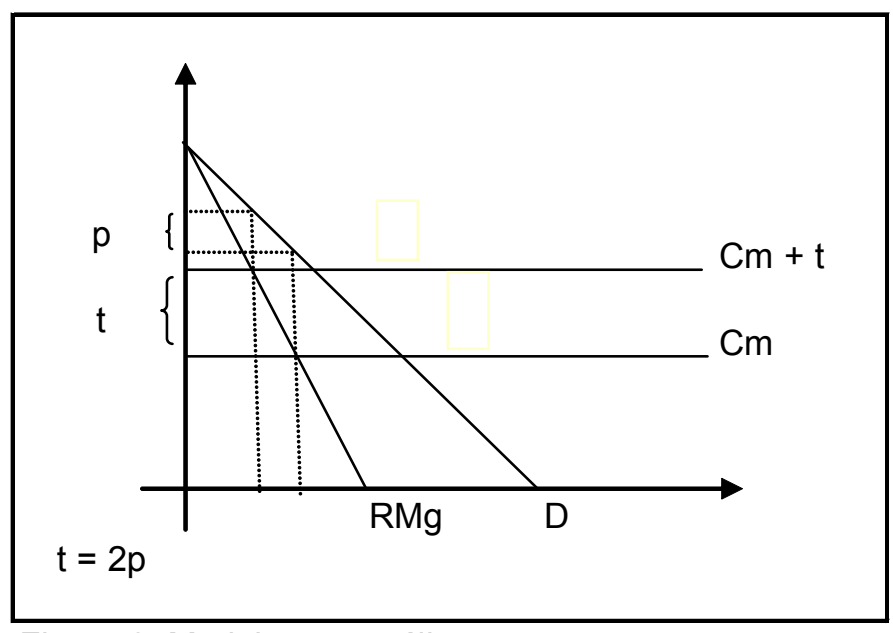

Fonte: VARIAN, 1999, p 441

Por sua vez, se a indústria e o varejo aplicarem um percentual fixo de markup no preço do produto, os valores dos coeficientes $\beta_{1}$ e $\beta_{2}$ serão superiores a 1, visto que uma elevação dos preços dos insumos em termos absolutos é acrescida de variação da margem que incide sobre esses custos, resultando em um aumento de preços maior que a variação do preço dos insumos. Estratégias de precificação com percentual fixo são prática comum em mercados oligopolizados, conforme há muito reportado por Hall e Hitch (1937), estando, portanto, mais distantes do modelo competitivo (Carman; Sexton, 2005). 
De maneira implícita, o modelo assume que as mudanças de preços no varejo são provocadas por alterações do preço pago ao produtor (Capps e Sherwell, 2005 ; Parrot e Eastwood e Brooker, 2001). Na especificação funcional do modelo, a variável 'preço no varejo' depende das oscilações no correr do tempo do preço da matéria-prima (Houck, 1977). Desse modo, o modelo assume implicitamente que as mudanças na demanda se traduzem em ajustes de quantidade, que são transmitidos pela cadeia produtiva, até a formação de preços da matéria-prima.

Outra premissa do modelo é que se os custos marginais forem constantes na indústria e varejo e a estrutura do mercado seguir o modelo competitivo, os coeficientes $\beta_{1}$ e $\beta_{2}$ assumirão valores próximos de 1 (Carman; Sexton, 2005). Essa observação está baseada no modelo de formação de preços de alimentos no varejo de Heien (1980). O equilíbrio na formação de preços do varejo, dados os retornos constantes de escala e função de produção 'Leontief', seria obtido através da aplicação de markup do varejista sobre commodities (Heien, 1980). A hipótese de retornos constantes de escala e custos marginais constantes sugere que a tecnologia envolvida na distribuição e comercialização de produtos no varejo muda lentamente em comparação a outros setores (Parrot; Eastwood; Brooker, 2001). No caso brasileiro, a premissa de custos marginais constantes é pouco plausível, dado que os custos de transporte e energia, entre outros, podem ser variáveis, assim como houve, nos últimos 15 anos, grande mudança tecnológica em laticínios, logística e varejo. Sob esse aspecto, é desejável incluir a variável 'custo de comercialização’ na especificação do modelo. Para Heien (1980), faz mais sentido assumir que mudanças nos preços do varejo refletem alterações em toda cadeia e que essas mudanças de custo são transmitidas para o consumidor.

Alguns autores, como Aguiar e Santana, optaram por utilizar o modelo de Houck a partir da transformação logarítmica dos preços, e o resultado acaba refletindo a transmissão da variação do preço (Aguiar; Santana, 2002). Essa abordagem não será seguida neste teste para preservar as informações fornecidas sobre estratégias de preços a partir da utilização dos valores nominais dos dados. 


\subsection{Tratamento dos dados}

Considerando-se a importância dos dados regionais para medir o poder de mercado dos intermediários da cadeia, foram utilizados os preços pagos ao produtor no estado de São Paulo (Cepea/USP, 2006) e os preços pagos pelo consumidor no varejo na cidade de São Paulo (Fipe, 2006) no período de dezembro de 1999 a dezembro de 2005, totalizando 73 meses - na prática, são utilizados 72, visto que o mês inicial só é empregado para calcular a primeira diferença da série. O índice escolhido como proxy para as alterações no custo de comercialização do varejo foi o IPC da Fipe ${ }^{4}$.

Os resultados apresentam o comportamento de três grandes marcas de leite longa vida na cidade de São Paulo. Essas marcas serão identificadas como $\mathrm{X}, \mathrm{Y}$ e $\mathrm{Z}$. As marcas $\mathrm{X}$ e $\mathrm{Y}$ são de duas grandes processadoras do estado e a marca $Z$ é uma das líderes nacionais, com leite processado em todos os estados do País. Adicionalmente, serão apresentados os resultados do teste para o leite pasteurizado tipo B e $\mathrm{C}$, nas quais os produtores são do estado. Para o leite tipo B, será empregado também o preço pago ao produtor pelo leite $C$ que, nesse caso, funcionará como uma proxy do preço da matéria-prima desse tipo de pasteurizado.

Para confirmar que mudanças de preços pagos ao produtor provocam alterações de preço no varejo, é aplicado o teste de Granger. O teste de causalidade de Granger procura apenas inferir se valores passados e presentes da variável explicativa ajudam a prever valores futuros da variável explicada (Enders, 2004). Assim, a hipótese nula do teste é construída para verificar se, neste caso, a variável preço do produtor não ajuda a prever valores do preço no varejo ${ }^{5}$. Por meio do teste de Granger, são verificados os indícios de causalidade previstos

\footnotetext{
${ }^{4}$ Dentre os trabalhos pesquisados, foram encontrados diversos períodos de análise, como 49 meses (Carman; Sexton, 2005), passando por 67 meses (Parrot; Eastwood; Brooker, 2001) e 94 meses (Capps; Sherwell, 2005).

${ }^{5} \mathrm{O}$ resultado esperado para esse teste é um elevado valor da estatística $\mathrm{F}$ para rejeição dessa hipótese nula. Devido a sua própria estrutura, o teste apresenta limitações, podendo estabelecer relações causais espúrias. Resultados de Granger que indicam causalidade nas duas direções - preço pago ao produtor causa preço no varejo e vice-versa - também são comuns (Eviews, 1998).
} 
na premissa do modelo. A hipótese nula é rejeitada para todos os casos, conforme descrito na Tabela 3.

Tabela 3 - Teste de causalidade de Granger

\begin{tabular}{lccc}
\hline Hipótese nula & lags & estatística F & p valor \\
\hline Preço produtor não granger-causa preço marca X & 4 & 4,5708 & 0,0205 \\
$\begin{array}{l}\text { Preço produtor não granger-causa preço marca Y } \\
\text { Preço produtor não granger-causa preço marca Z }\end{array}$ & 4 & 3,1465 & 0,0027 \\
$\begin{array}{l}\text { Preço produtor não granger-causa preço } \\
\text { pasteurizado C }\end{array}$ & 3 & 3,5823 & 0,0334 \\
$\begin{array}{l}\text { Preço produtor não granger-causa preço } \\
\text { pasteurizado B }\end{array}$ & 3 & 4,1154 & 0,0099 \\
\hline
\end{tabular}

Fonte: elaboração própria

Com base nos preços pagos ao produtor coletados pelo Cepea/ Esalq-USP, o modelo foi replicado, utilizando o preço pago ao produtor em São Paulo, Rio Grande do Sul, Minas Gerais (maior produtor do País) e a média Brasil. Os melhores ajustes, considerando-se o problema de autocorrelação, foram obtidos quando foi utilizado o preço pago ao produtor em São Paulo. Entretanto, a elevada correlação entre os preços pagos ao produtor em São Paulo e na média nacional, conforme ilustrado na Figura 3, sugere que os resultados aqui reportados são generalizáveis para o restante do País.

Nos trabalhos pesquisados, não foi encontrado qualquer tipo de tratamento para deflacionar os preços. Capps e Sherwell são explícitos quanto à utilização dos dados nominais (Capps; Sherwell, 2005). A pesquisa de Aguiar e Santana que utilizou dados de janeiro de 1987 a junho de 1998, inclusive, atribui ao período de inflação até 1994 uma influência na formação das expectativas de aumento dos preços (Aguiar; Santana, 2002).

Para este artigo, foram adicionalmente testados modelos com dados deflacionados, mas os resultados obtidos com os preços deflacionados (valor presente em dez/05) desencorajam o emprego desse tratamento, uma vez que ele aumenta a autocorrelação dos dados e diminui o poder explicativo do modelo. O modelo deflacionado causou uma distribuição menos linear para os dois tipos de leite e, não obstante, já foi 
testado tanto no modelo original quanto no dessazonalizado através do índice de custo $\left(\mathrm{c}_{\mathrm{t}}\right)$. Este índice não se mostrou relevante para o caso do longa vida. No caso do pasteurizado, como o índice foi aplicado na especificação, qualquer tratamento para deflacionar os dados é, de fato, uma redundância, já que o índice de custo foi empregado no modelo original e dessazonalizado. Vale lembrar que a principal finalidade do teste de Houck está em medir a simetria das transmissões de aumento e diminuições dos preços do produtor ao consumidor final, independente sejam as causas dessas oscilações, aumentos inflacionários ou aumentos reais de custos na cadeia.

Figura 3 - Preço nominal recebido pelo produtor por litro de leite C

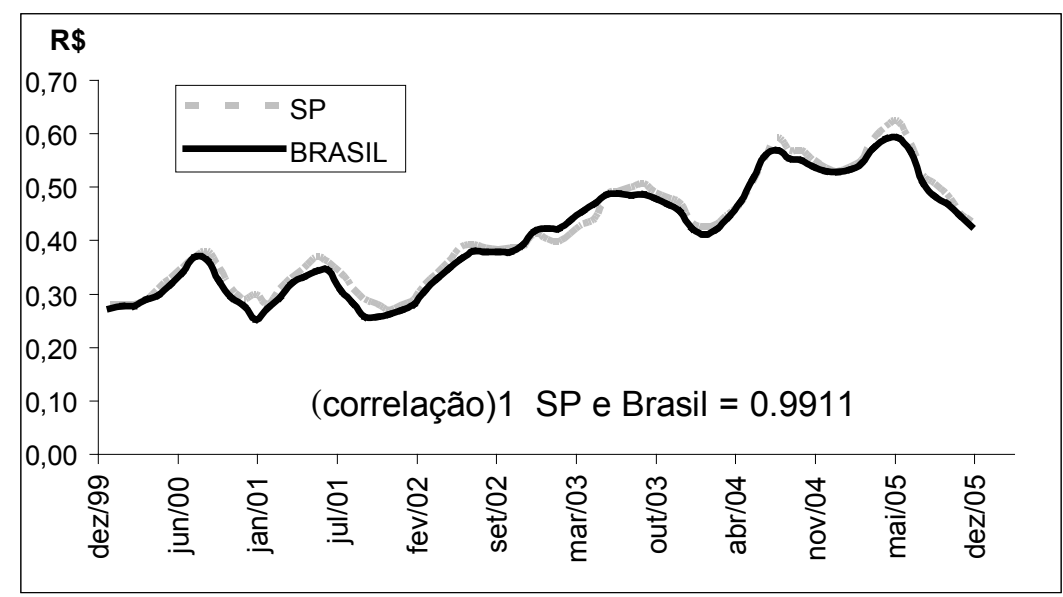

Fonte: CEPEA (ESALQ/USP) e EMBRASA, 2006

Nota1: correlação elaboração própria

Houck chama atenção para o fato de uma variável explicativa ser dividida em duas: acréscimo e decréscimo. Isso geralmente acaba aumentando o problema de autocorrelação temporal entre os componentes da série (Houck, 1977). A estrutura do termo de erro da regressão linear da variação do preço no varejo em função das variáveis explicativas acréscimo e decréscimo no preço pago ao produtor é a de um AR(1). Isso significa que o resíduo deixa de ser aleatório e passa a depender do valor do termo de erro ocorrido no 
período anterior, sendo, portanto, um processo auto-regressivo de $1^{\mathrm{a}}$ ordem (Vasconcellos; Alves, 2000).

Existem vários métodos de correção para problemas de autocorrelação AR(1). A maioria dos trabalhos analisados utilizou o procedimento iterativo Cochrane-Orcutt (Aguiar e Santana, 2002; Carman e Sexton, 2005; Capps e Sherwell, 2005). Por meio desse procedimento, o verdadeiro valor de $\rho$ que não é conhecido é estimado por mínimos quadrados ordinários (MQO) através de uma regressão nos resíduos obtidos e defasados, conforme a especificação (Vasconcellos; Alves, 2000, p. 117):

$$
\hat{\rho}=\frac{\sum_{t=2}^{n} e_{t} \times e_{t-1}}{\sum_{t=2}^{n} e_{t}^{2}}
$$

A partir daí, é gerada a equação transformada, na qual a única diferença são os valores das variáveis $\mathrm{Y}$ e X:

$$
Y_{t}-\hat{\rho} Y_{t-1}=\beta_{1}(1-\hat{\rho})+\beta_{2}\left(X_{t}-\hat{\rho} X_{t-1}\right)+\mu_{t}
$$

Aplica-se MQO para a equação transformada, e o procedimento é repetido inúmeras vezes até que o valor estimado de $\rho$ mude pouco em relação à última iteração (Wooldridge, 2003). Esse procedimento, no qual se aplica MQO a partir da equação transformada, é conhecido como mínimos quadrados generalizados (Wooldridge, 2003).

Alguns autores preferiram outros métodos não-lineares, empregando procedimentos baseados em algoritmos (Frigon e Doyon e Romain, 1999; Parrot e Eastwood e Brooker, 2001). No teste empírico realizado nesta pesquisa, os resultados com métodos de mínimos quadrados generalizados e modelos não-lineares foram quase idênticos, o que confere robustez às conclusões. Dada a indiferença dos métodos neste caso, optou-se por utilizar o método de Cochrane-Orcutt, na qual a estatística $\mathrm{R}^{2}$ pode ser utilizada sem restrições (Frigon; Doyon; Romain, 1999). Os resultados pelo método de máxima-verossimilhança serão apresentados ao final da seção de resultados.

Em todos os trabalhos pesquisados, foi utilizado o teste de DurbinWatson (DW) para medir a eficiência do método de correção de auto- 
correlação das séries (Aguiar e Santana, 2002; Capps e Sherwell, 2005; Carman e Sexton, 2005; Frigon e Doyon e Romain, 1999). O teste DW pode ser empregado para testar autocorrelação de $1^{\text {a }}$ ordem, o AR(1).

É sabido que existem testes mais adequados para captar se a série é estacionária e se seus resíduos são ruídos brancos, sobretudo a estatística Q de Ljung-Box (Enders, 2004). Nas tabelas de resultados dos modelos, são mostrados os valores de Q acumulados no $\operatorname{lag} 4,8,12$ e 16. Para se obter um processo ruído branco, deve-se encontrar valores pequenos para a estatística de Ljung-Box. Elevados valores deste teste com baixa significância ( $\mathrm{p}$ valor) são indicadores de autocorrelação na série. Deve-se destacar que não foram encontrados testes de autocorrelação dos resíduos em nenhum dos trabalhos pesquisados (Aguiar e Santana, 2002; Capps e Sherwell, 2005; Carman e Sexton, 2005; Frigon e Doyon e Romain, 1999). Neste trabalho, serão reportados os resultados dos dois testes, considerando-se que, apesar das restrições de aplicação, o teste de DW é o mais difundido.

Para se obter o número de meses de defasagem (lags) estatisticamente significativos de acréscimo e decréscimo de preços, empregou-se o modelo de Almon lag, assim como na maioria dos trabalhos pesquisados (Aguiar; Santana, 2002). Almon lag é como é conhecida a defasagem com distribuição polinomial (Eviews, 1998). Analisam-se quais coeficientes defasados são significantes ou não. Para alguns autores, porém, qualquer método de seleção de defasagens é arbitrário e todos os resultados devem ser reportados (Frigon; Doyon; Romain, 1999). Nesta pesquisa, optou-se por seguir a sugestão de Carman e Sexton, eliminando as defasagens sem significância estatística (Carman; Sexton, 2005).

Nos EUA, o sistema de produção atenua a sazonalidade na produção de leite, mas esse não é o caso do Brasil. Correções de sazonalidade só foram encontradas no trabalho de Parrot et al. (2001), em que o modelo original de Houck é alterado, por meio do acréscimo de um parâmetro de quantidade de leite distribuído pela indústria (Parrot; Eastwood; Brooker, 2001). Considerando-se a falta de dados a esse respeito, essa alteração não parece adequada para o propósito do presente trabalho.

Não existe um método estatístico de dessazonalização que seja, de maneira geral, superior aos demais. A análise econômica dos resultados 
ainda é a principal ferramenta para seleção do método escolhido (Picchetti, 2003). Correções de sazonalidade implicam necessariamente em um procedimento de duas etapas distintas: primeiro, o tratamento da sazonalidade nos dados e, só a posteriori, a estimação do processo auto-regressivo (Enders, 2004). Esse procedimento é reforçado neste caso, pois as variáveis explicativas são construídas a partir das variações absolutas de preços pagos ao produtor e não diretamente dos valores absolutos desses preços. Neste teste empírico, foram utilizadas duas técnicas de dessazonalização dos dados: a de médias móveis por meio de sazonalidade multiplicativa e o algoritmo X-12. O tratamento por médias móveis apresentou o menor problema de autocorrelação e foi aplicado para dessazonalizar a série de preços pago ao produtor e a série de preços no varejo.

Outro ponto importante do modelo diz respeito ao emprego do coeficiente de tendência $\beta_{0} \mathrm{t}$. No caso do leite longa vida, esse coeficiente se mostrou sem significância estatística. Com efeito, sua inclusão na especificação aumentou a variabilidade (desvio padrão) das demais variáveis explicativas. Essa variável parece funcionar como um componente de "flutuação" (um drift). Em trabalhos aplicados, é muito difícil descartar o uso do $\beta_{0}$, uma vez que, caso esse seja diferente de zero, o $\beta_{1}$ estimado é um coeficiente enviesado do verdadeiro $\beta_{1}$, pois seu valor estará no termo de erro (Wooldridge, 2003) Por precaução, serão apresentados os resultados dos modelos para o leite longa vida com as duas especificações, com e sem o coeficiente de tendência $\beta_{0}$ t. Entretanto, conforme será observado adiante, o uso ou não de tendência não interfere na distribuição dos resíduos (vide teste Q nas tabelas 4 e 5).

Na seção seguinte, são apresentados os resultados do modelo original de Houck sem tratamento e os resultados de um modelo dessazonalizado por médias móveis. Os resultados também apresentarão o comportamento de três grandes marcas de leite longa vida na cidade de São Paulo. Essas marcas serão identificadas como X, Y e Z. As marcas X e Y são de duas grandes processadoras do estado e a marca $Z$ é uma das líderes nacionais, com leite processado em todos os estados do País. Por fim, serão apresentados os resultados do teste para o leite pasteurizado tipo B e C, nas quais os produtores são do estado. Para o leite tipo 
$\mathrm{B}$, será empregado também o preço pago ao produtor pelo leite $\mathrm{C}$ que, nesse caso, funcionará como uma proxy do preço da matéria-prima desse tipo de pasteurizado.

\section{Resultados}

\subsection{Leite Longa Vida}

Para o leite longa vida, os valores de $\mathrm{R}^{2}$ do modelo original e do modelo dessazonalizado variam de 0,79 a 0,91 , indicando que o poder explicativo dessa análise é significativo (Tabelas 4 e 5). $\mathrm{O}$ índice de custo de mercado mostrou-se não-significativo para o leite longa vida e foi retirado da estrutura do teste. Esse comportamento do índice também ocorreu em outros testes pesquisados (Carman; Sexton, 2005). O uso do coeficiente $\beta_{0}$ que assume a forma de tendência só produziu alguma diferença no resultado quando foi incluído no modelo da marca X; para as demais marcas, não houve diferença relevante.

De acordo com o teste $\mathrm{Q}$ encontrado nas Tabelas 4 e 5, a autocorrelação foi corrigida para a marca X nos modelos dessazonalizados com e sem tendência, e a distribuição dos resíduos é independente do tempo. Já para a marca Z, o modelo original apresentou menor problema de correlação temporal que o modelo dessazonalizado, mas a estatística Q indica que as autocorrelações dos resíduos no lag 8 não são significantes a $5 \%$ de nível de confiança, mas são significantes quando o nível de confiança for de $10 \%$. Já para a marca Y, não foi possível eliminar a autocorrelação, e os resíduos apresentaram correlação temporal positiva, tipo mais comum de autocorrelação (Enders, 2004). Para este caso, existem oportunidades de aperfeiçoamento no ajuste do modelo na escolha de um índice de custo mais adequado e na aplicação de outro método de dessazonalização.

Não foi identificada defasagem significativa na velocidade de transmissão de acréscimo ou decréscimo de preço para nenhum desses modelos analisados para nenhuma das três marcas. Portanto, em relação à velocidade de transmissão da oscilação de preço do produtor ao consumidor final, não ficou caracterizado poder de mercado da indústria ou varejo para o leite longa vida. 
Tabela 4 - Resultados para o leite longa vida com $\beta_{0}$ t na especificação

\begin{tabular}{|c|c|c|c|c|c|c|}
\hline \multirow{2}{*}{ Longa Vida } & \multicolumn{3}{|c|}{ Modelo original } & \multicolumn{3}{|c|}{ Modelo dessazonalizado } \\
\hline & Marca X & Marca Y & Marca Z & Marca X & Marca Y & Marca Z \\
\hline $\mathrm{R}^{2}$ & 0,902 & 0,810 & 0,832 & 0,918 & 0,827 & 0,877 \\
\hline$\beta_{0}$ & 0,008 & 0,004 & 0,019 & 0,006 & $-0,004$ & 0,007 \\
\hline $\begin{array}{l}\text { desvio } \\
\text { padrão }\end{array}$ & 0,009 & 0,010 & 0,008 & 0,007 & 0,008 & 0,007 \\
\hline$\beta_{1}$ & 1,554 & 1,822 & 0,905 & 1,937 & 2,438 & 2,144 \\
\hline $\begin{array}{l}\text { desvio } \\
\text { padrão }\end{array}$ & 0,602 & 0,742 & 0,599 & 0,358 & 0,437 & 0,355 \\
\hline$\beta_{2}$ & 1,770 & 2,144 & 3,140 & 2,035 & 2,254 & 2,814 \\
\hline $\begin{array}{l}\text { desvio } \\
\text { padrão }\end{array}$ & 0,491 & 0,589 & 0,479 & 0,314 & 0,377 & 0,309 \\
\hline$\beta_{1}=\beta_{2}{ }^{1}$ & não rejeita & não rejeita & rejeita & $\begin{array}{l}\text { não } \\
\text { rejeita }\end{array}$ & $\begin{array}{c}\text { não } \\
\text { rejeita }\end{array}$ & $\begin{array}{c}\text { não } \\
\text { rejeita }\end{array}$ \\
\hline valor $\mathrm{p}$ & 0,818 & 0,777 & 0,017 & 0,848 & 0,760 & 0,182 \\
\hline Almon lag $\beta_{1}$ & 0 & 0 & 0 & 0 & 0 & 0 \\
\hline valor t & 4,419 & 4,348 & 4,993 & 3,631 & 4,958 & 4,538 \\
\hline Almon lag $\beta_{2}$ & 0 & 0 & 0 & 0 & 0 & 0 \\
\hline valor t & 3,207 & 2,448 & 4,412 & 4,105 & 2,903 & 5,833 \\
\hline$\beta_{1}=1^{1}$ & não rejeita & não rejeita & $\begin{array}{l}\text { não } \\
\text { rejeita }\end{array}$ & rejeita & rejeita & rejeita \\
\hline valor $\mathrm{p}$ & 0,360 & 0,272 & 0,874 & 0,011 & 0,002 & 0,002 \\
\hline$\beta_{2}=1^{1}$ & não rejeita & não rejeita & rejeita & rejeita & rejeita & rejeita \\
\hline valor $\mathrm{p}$ & 0,122 & 0,056 & 0,000 & 0,002 & 0,001 & 0,000 \\
\hline $\mathrm{D}-\mathrm{W}$ & 1,453 & 1,453 & 1,515 & 1,651 & 1,708 & 1,726 \\
\hline $\mathrm{Q}_{4}$ & 8,337 & 10,213 & 8,683 & 3,606 & 5,169 & 7,066 \\
\hline valor $\mathrm{p}$ & 0,080 & 0,037 & 0,070 & 0,462 & 0,270 & 0,132 \\
\hline $\mathrm{Q}_{8}$ & 20,343 & 18,384 & 18,211 & 12,369 & 17,708 & 17,312 \\
\hline valor $\mathrm{p}$ & 0,009 & 0,019 & 0,020 & 0,135 & 0,024 & 0,027 \\
\hline $\mathrm{Q}_{12}$ & 21,330 & 18,759 & 18,909 & 16,750 & 24,708 & 24,389 \\
\hline valor $\mathrm{p}$ & 0,046 & 0,095 & 0,091 & 0,159 & 0,016 & 0,018 \\
\hline $\mathrm{Q}_{16}$ & 23,007 & 19,542 & 19,496 & 18,017 & 27,785 & 26,463 \\
\hline valor $\mathrm{p}$ & 0,114 & 0,242 & 0,244 & 0,323 & 0,034 & 0,048 \\
\hline
\end{tabular}

Nota 1: nível de significância de 5\%

Fonte: elaboração própria 
A diferença nos resultados existe quando o modelo com coeficiente de tendência é comparado com o modelo sem esse coeficiente. $\mathrm{O}$ uso deste último aumenta a variabilidade dos coeficientes $\beta_{1}$ e $\beta_{2}$ e altera alguns resultados dos testes de hipóteses. Partindo do menor problema de autocorrelação observado no teste $\mathrm{Q}$, os modelos com melhor especificação são o modelo original sem coeficiente de tendência para a marca Y e Z e o modelo dessazonalizado com coeficiente de tendência para a marca X.

Com o $\beta_{0}$ na especificação do modelo da marca $X$, por exemplo, não é possível afirmar que há assimetria de resposta a aumentos e decréscimos de preços. Esse parece ser um resultado plausível, pois a marca $\mathrm{X}$ atua no mesmo mercado que as demais marcas e caso ela transmita mais os aumentos de preço que os concorrentes, provavelmente perderá participação. Já para o modelo original com coeficiente de tendência da marca $Z$, os resultados dos coeficientes $\beta_{1}$ e $\beta_{2}$ são contraditórios, visto que, neste caso, os aumentos de preços seriam repassados como um markup nominal e os decréscimos, como um percentual fixo de markup.

Por tais motivos, a análise subseqüente estará centrada nos resultados obtidos a partir desses modelos (modelo original sem coeficiente de tendência para a marca $\mathrm{Y}$ e $\mathrm{Z}$ e modelo dessazonalizado com coeficiente de tendência para a marca $X)$. Para os modelos sem coeficiente de tendência, os resultados para os testes de hipóteses $\left(\beta_{1}=\beta_{2}, \beta_{1}=1\right.$ e $\beta_{2}=1$ ) são idênticos entre os modelos sem correção e os modelos dessazonalizados para cada marca. Assim, para a série utilizada neste teste, a correção por médias móveis adotada para dessazonalização não alterou o resultado geral do teste. É interessante notar que os valores do teste DW indicam um menor problema de autocorrelação para todos os modelos dessazonalizados, resultado oposto ao encontrado no teste $\mathrm{Q}$ para as marcas Y e Z. Os valores do teste DW, inclusive, estão próximos aos encontrados nos testes de outras referências (Aguiar e Santana, 2002; Carman e Sexton, 2005).

Em relação à simetria da transmissão dos coeficientes de acréscimo e decréscimo de preço, não é rejeitada a relação de equivalência da magnitude dos coeficientes $\left(\beta_{1}=\beta_{2}\right)$ com $5 \%$ de nível de significância para as três marcas em quaisquer dos modelos selecionados. Para essas marcas, o comportamento de preço no varejo para aumentos e quedas de preços pagos ao produtor foi equivalente. O preço do leite no varejo 
em São Paulo no período analisado não apresentou uma tendência de transmissão maior para os aumentos que para as quedas de preços para o consumidor dessas marcas.

Tabela 5 - Resultados para o leite longa vida sem $\beta_{0}$ t na especificação

\begin{tabular}{|c|c|c|c|c|c|c|}
\hline \multirow{2}{*}{ Longa Vida } & \multicolumn{3}{|c|}{ Modelo original } & \multicolumn{3}{|c|}{ Modelo dessazonalizado } \\
\hline & Marca X & Marca Y & Marca Z & Marca X & Marca Y & Marca Z \\
\hline $\mathrm{R}^{2}$ & 0,894 & 0,806 & 0,789 & 0,911 & 0,829 & 0,872 \\
\hline$\beta_{1}$ & 2,081 & 2,091 & 2,160 & 2,207 & 2,277 & 2,466 \\
\hline $\begin{array}{l}\text { desvio } \\
\text { padrão }\end{array}$ & 0,207 & 0,247 & 0,214 & 0,178 & 0,216 & 0,177 \\
\hline$\beta_{2}$ & 1,417 & 1,975 & 2,329 & 1,851 & 2,350 & 2,616 \\
\hline $\begin{array}{l}\text { desvio } \\
\text { padrão }\end{array}$ & 0,337 & 0,406 & 0,349 & 0,252 & 0,307 & 0,250 \\
\hline$\beta_{1}=\beta_{2}^{1}$ & rejeita & $\begin{array}{l}\text { não } \\
\text { rejeita }\end{array}$ & $\begin{array}{c}\text { não } \\
\text { rejeita }\end{array}$ & rejeita & $\begin{array}{c}\text { não } \\
\text { rejeita }\end{array}$ & $\begin{array}{c}\text { não } \\
\text { rejeita }\end{array}$ \\
\hline valor $\mathrm{p}$ & 0,000 & 0,543 & 0,311 & 0,001 & 0,543 & 0,131 \\
\hline Almon lag $\beta_{1}$ & 0 & 0 & 0 & 0 & 0 & 0 \\
\hline valor t & 4,419 & 4,348 & 4,993 & 3,631 & 4,958 & 4,538 \\
\hline Almon lag $\beta_{2}$ & 0 & 0 & 0 & 0 & 0 & 0 \\
\hline valor t & 3,207 & 2,448 & 4,412 & 4,105 & 2,903 & 5,833 \\
\hline$\beta_{1}=1^{1}$ & rejeita & rejeita & rejeita & rejeita & rejeita & rejeita \\
\hline valor $\mathrm{p}$ & 0,000 & 0,000 & 0,000 & 0,000 & 0,000 & 0,000 \\
\hline$\beta_{2}=1^{1}$ & não rejeita & rejeita & rejeita & rejeita & rejeita & rejeita \\
\hline valor $\mathrm{p}$ & 0,221 & 0,019 & 0,000 & 0,001 & 0,000 & 0,000 \\
\hline $\mathrm{D}-\mathrm{W}$ & 1,465 & 1,459 & 1,611 & 1,676 & 1,704 & 1,754 \\
\hline $\mathrm{Q}_{4}$ & 7,933 & 9,940 & 4,941 & 3,309 & 5,332 & 6,302 \\
\hline valor $\mathrm{p}$ & 0,094 & 0,041 & 0,293 & 0,507 & 0,255 & 0,178 \\
\hline $\mathrm{Q}_{8}$ & 19,972 & 17,861 & 14,762 & 10,534 & 18,292 & 15,381 \\
\hline valor $\mathrm{p}$ & 0,010 & 0,022 & 0,064 & 0,230 & 0,019 & 0,052 \\
\hline $\mathrm{Q}_{12}$ & 21,048 & 18,231 & 17,010 & 15,590 & 25,291 & 22,938 \\
\hline valor $\mathrm{p}$ & 0,050 & 0,109 & 0,149 & 0,211 & 0,014 & 0,028 \\
\hline $\mathrm{Q}_{16}$ & 23,425 & 19,089 & 17,196 & 17,300 & 28,234 & 24,874 \\
\hline valor $\mathrm{p}$ & 0,103 & 0,264 & 0,373 & 0,366 & 0,030 & 0,072 \\
\hline
\end{tabular}

Nota 1: nível de significância de $5 \%$

Fonte: elaboração própria 
Se os movimentos de elevação e queda nos preços são simétricos entre si, os valores repassados para o consumidor não acompanham os mesmos valores absolutos das oscilações do preço ao produtor. Um Real de aumento ou diminuição no preço pago ao produtor não é repassado nessa grandeza para o consumidor. Com $5 \%$ de nível de significância, a hipótese de $\beta_{1}$ ou $\beta_{2}$ igual a 1 é rejeitada. Como os coeficientes de acréscimo e decréscimo são maiores que 1, os intermediários aplicam um markup percentual fixo, o que é uma evidência de imperfeição de mercado (Carman; Sexton, 2005). A precificação com markup percentual, conforme exposto na seção 3, é comum em mercados oligopolistas, em que as empresas gozam de algum poder de mercado, mas cujo comportamento difere da precificação de monopólio.

\subsection{Leite pasteurizado}

Os resultados para o mercado de leite pasteurizado tipo B e C, apresentados na Tabela 6 , indicam que o coeficiente de tendência $\beta_{0}$ e o coeficiente de custo mostraram-se significativos e foram incluídos na especificação. Os preços finais do leite pasteurizado tipo B e tipo C são bastante próximos, sendo o primeiro sempre um pouco mais caro que o segundo devido às suas especificações técnicas. Os resultados de defasagem e análise de coeficientes são idênticos para os dois tipos de leite. O modelo original apresentou menor problema de autocorrelação temporal, ocasionado por sua distribuição mais linear que a série dessazonalizada, melhor captada pelo processo de correção (vide figura 5). A distribuição dos resíduos é um ruído branco para os todos os modelos do leite pasteurizado, conforme indicam os baixos valores da estatística Q em todos os lags (vide Tabela 6).

Em relação à velocidade da transmissão das oscilações de preço, é identificada uma defasagem para a transmissão das diminuições de preço do produtor ao consumidor. No caso do modelo sem correção, essa defasagem é de cinco meses e, para o modelo dessazonalizado, de um mês. A diferença de defasagens entre os modelos é, muito provavelmente, originada pela demora da transmissão de queda de preços entre os períodos de safra e entressafra no modelo sem correção. Dado esse fenômeno, o mais recomendável é analisar o modelo sem variações sazonais e esse indica uma defasagem diferente entre o coeficiente de acréscimo e o coeficiente de decréscimo de preço. Enquanto a transmissão do primeiro se dá no mesmo mês, a do segundo leva um mês, evidenciando imperfeição de mercado. 
Tabela 6 - Resultados para o leite pasteurizado

\begin{tabular}{|c|c|c|c|c|}
\hline \multirow{2}{*}{ Pasteurizado } & \multicolumn{2}{|c|}{ Modelo original } & \multicolumn{2}{|c|}{ Dessazonalizado } \\
\hline & Tipo C & Tipo B & Tipo C & Tipo B \\
\hline $\mathrm{R}^{2}$ & 0,9895 & 0,9680 & 0,9781 & 0,9807 \\
\hline$\beta_{0}$ & 0,0024 & 0,0055 & 0,0046 & 0,0085 \\
\hline desvio padrão & 0,0019 & 0,0028 & 0,0029 & 0,0036 \\
\hline$\beta_{1}$ & 0,6291 & 0,5401 & 0,3935 & 0,3801 \\
\hline desvio padrão & 0,1706 & 0,2555 & 0,1245 & 0,1554 \\
\hline$\beta_{2}$ & 0,4780 & 0,5774 & 0,3860 & 0,5505 \\
\hline desvio padrão & 0,1727 & 0,2860 & 0,1247 & 0,1557 \\
\hline$c_{t}$ & 0,1288 & 0,2093 & 0,1290 & 0,1936 \\
\hline desvio padrão & 0,0136 & 0,0339 & 0,0204 & 0,0260 \\
\hline$\beta_{1}=\beta_{2}^{1}$ & não rejeita & não rejeita & não rejeita & não rejeita \\
\hline valor $\mathrm{p}$ & 0,4785 & 0,9061 & 0,9728 & 0,5565 \\
\hline Almon lag $\beta_{1}$ & 0 & 0 & 0 & 0 \\
\hline valor t & 3,1256 & 3,7566 & 3,4263 & 3,5288 \\
\hline Almon lag $\beta_{2}$ & 5 & 5 & 1 & 1 \\
\hline valor t & 3,6032 & 3,0107 & 3,9588 & 3,7397 \\
\hline$\beta_{1}=1^{1}$ & rejeita & não rejeita & rejeita & rejeita \\
\hline valor $\mathrm{p}$ & 0,0331 & 0,0762 & 0,0000 & 0,0002 \\
\hline$\beta_{2}=1^{1}$ & rejeita & não rejeita & rejeita & rejeita \\
\hline valor $\mathrm{p}$ & 0,0035 & 0,1439 & 0,0000 & 0,0052 \\
\hline$\beta_{1}=0,5^{1}$ & não rejeita & não rejeita & não rejeita & não rejeita \\
\hline valor p & 0,4516 & 0,8757 & 0,3954 & 0,4427 \\
\hline$\beta_{2}=0,5^{1}$ & não rejeita & não rejeita & não rejeita & não rejeita \\
\hline valor p & 0,8991 & 0,7875 & 0,3634 & 0,7468 \\
\hline $\mathrm{D}-\mathrm{W}$ & 2,0380 & 1,8950 & 1,5583 & 1,5799 \\
\hline $\mathrm{Q}_{4}$ & 1,3350 & 0,3948 & 2,2587 & 1,0057 \\
\hline valor $\mathrm{p}$ & 0,8554 & 0,9829 & 0,6883 & 0,9089 \\
\hline $\mathrm{Q}_{8}$ & 2,1977 & 0,7253 & 3,3137 & 1,1152 \\
\hline valor $\mathrm{p}$ & 0,9743 & 0,9995 & 0,9132 & 0,9974 \\
\hline $\mathrm{Q}_{12}$ & 3,6418 & 5,1229 & 6,8783 & 12,3064 \\
\hline valor $\mathrm{p}$ & 0,9891 & 0,9537 & 0,8655 & 0,4214 \\
\hline $\mathrm{Q}_{16}$ & 6,2958 & 7,3165 & 8,9306 & 14,4859 \\
\hline valor $\mathrm{p}$ & 0,9846 & 0,9667 & 0,9162 & 0,5626 \\
\hline
\end{tabular}

Nota $_{1}$ : nível de significância de $5 \%$

Fonte: elaboração própria 
A análise do valor dos coeficientes produz mais indícios a respeito do maior poder de mercado dos agentes intermediários na comercialização do leite pasteurizado em comparação ao leite longa vida. A hipótese de igualdade dos coeficientes $\beta_{1}=0,5$ e $\beta_{2}=0,5$, conforme apresentado na Tabela 6 , não é rejeitada. Esse resultado caracteriza um mercado com baixa concorrência, com características de precificação de monopólio. O teste para medir a igualdade dos coeficientes entre si não é rejeitado. Já o teste da hipótese de que os valores dos coeficientes sejam equivalentes a 1 é rejeitado para o tipo $\mathrm{C}$ e apresenta baixo valores de $\mathrm{p}$ para o tipo $\mathrm{B}$, tornado esta hipótese menos provável.

Em síntese, todos os resultados originários do teste para o leite pasteurizado tipo B e também para o tipo C apontam para um mercado bastante distante do modelo competitivo perfeito. Esses resultados podem apresentar algumas limitações. Em primeiro lugar, o resultado do valor do coeficiente sinalizar monopólio parte da premissa de uma curva de demanda linear, o que é um pressuposto razoável para pequenas variações de preços, mas inadequado para variações mais acentuadas. Outra limitação está na utilização do mesmo preço pago ao produtor (tipo C) os dois tipos de leite pasteurizado. Porém, dadas a similaridade dos produtos e a elevada correlação do comportamento de preço dos dois tipos, a utilização desses dados para a análise do leite $B$ não parece ser uma grande concessão.

\subsection{Observações adicionais sobre o modelo e a metodologia}

A respeito do método de correção do problema de autocorrelação da série, a diferença na melhor adequação de determinado modelo se dá em função da distribuição dos dados utilizados, no caso preço pago ao produtor e preço no varejo, representados na Figura 4.

O método de máxima-verossimilhança se mostrou mais adequado para distribuições menos lineares como o modelo dessazonalizado do leite pasteurizado. Conforme mostram os resultados do teste DW, o método Cochrane-Orcutt apresenta resultados mais robustos (menos autocorrelacionados) quando a distribuição da série é mais linear, en- 
quanto o método de máxima-verossimilhança se mostra mais adequado quando os dados apresentam uma distribuição menos linear.

Figura 5 - Dipersão entre o preço pago ao produtor e o preço de revenda do varejo de São Paulo (dez/99 à dez/05)
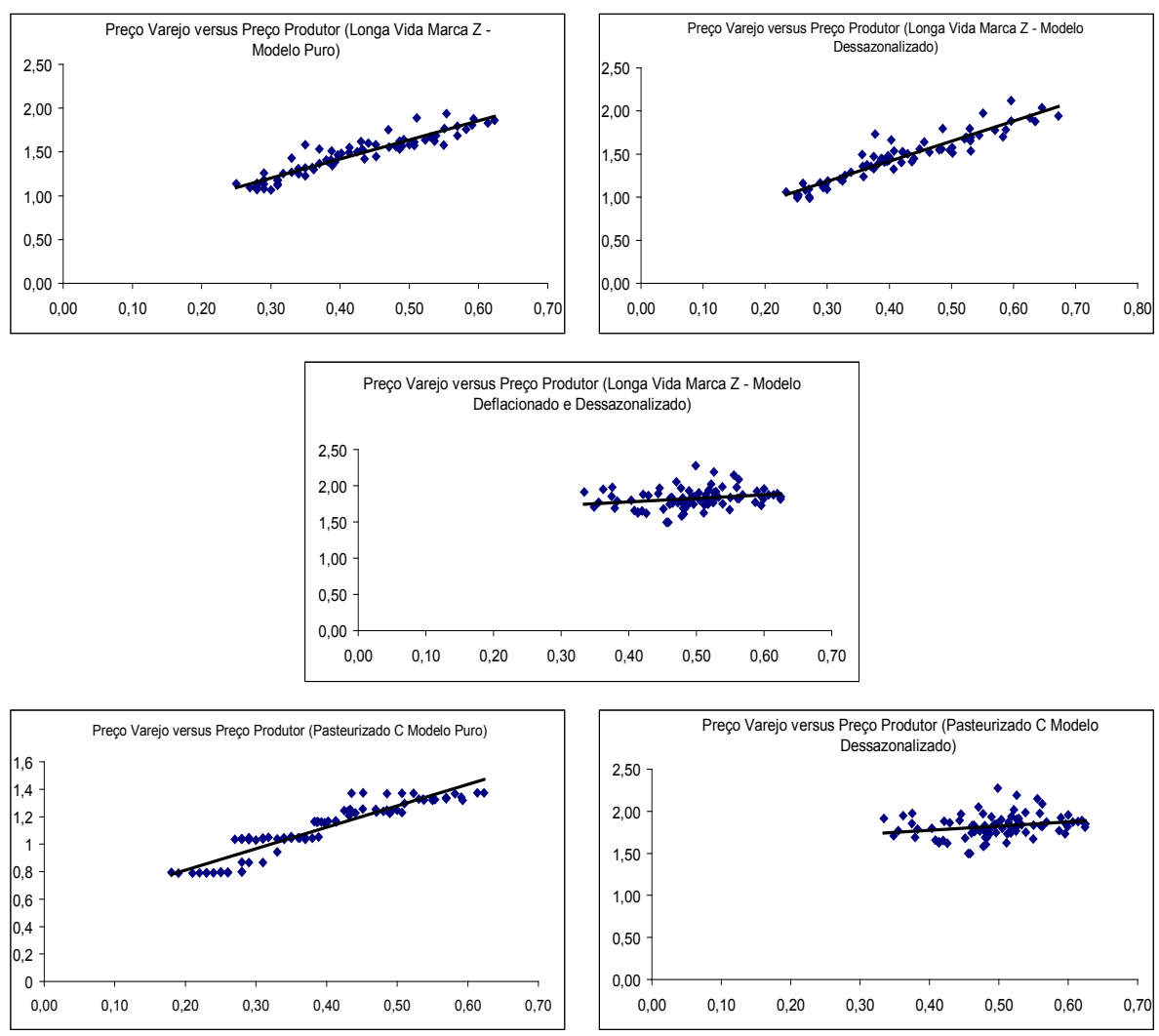

Fonte: Elaboração própria a partir de dados do CEPEA (ESALQ/USP). 2008

\section{Conclusão}

A importância de se entender o modelo de concorrência predominante em um mercado está relacionada ao conceito de bem-estar da sociedade (Motta, 2004). O vertiginoso crescimento das vendas de leite longa vida, absorvendo grande parte do mercado antes abastecido pelo leite pasteurizado, transformou o padrão de concorrência no Sistema Agroindustrial do Leite (SAL). 


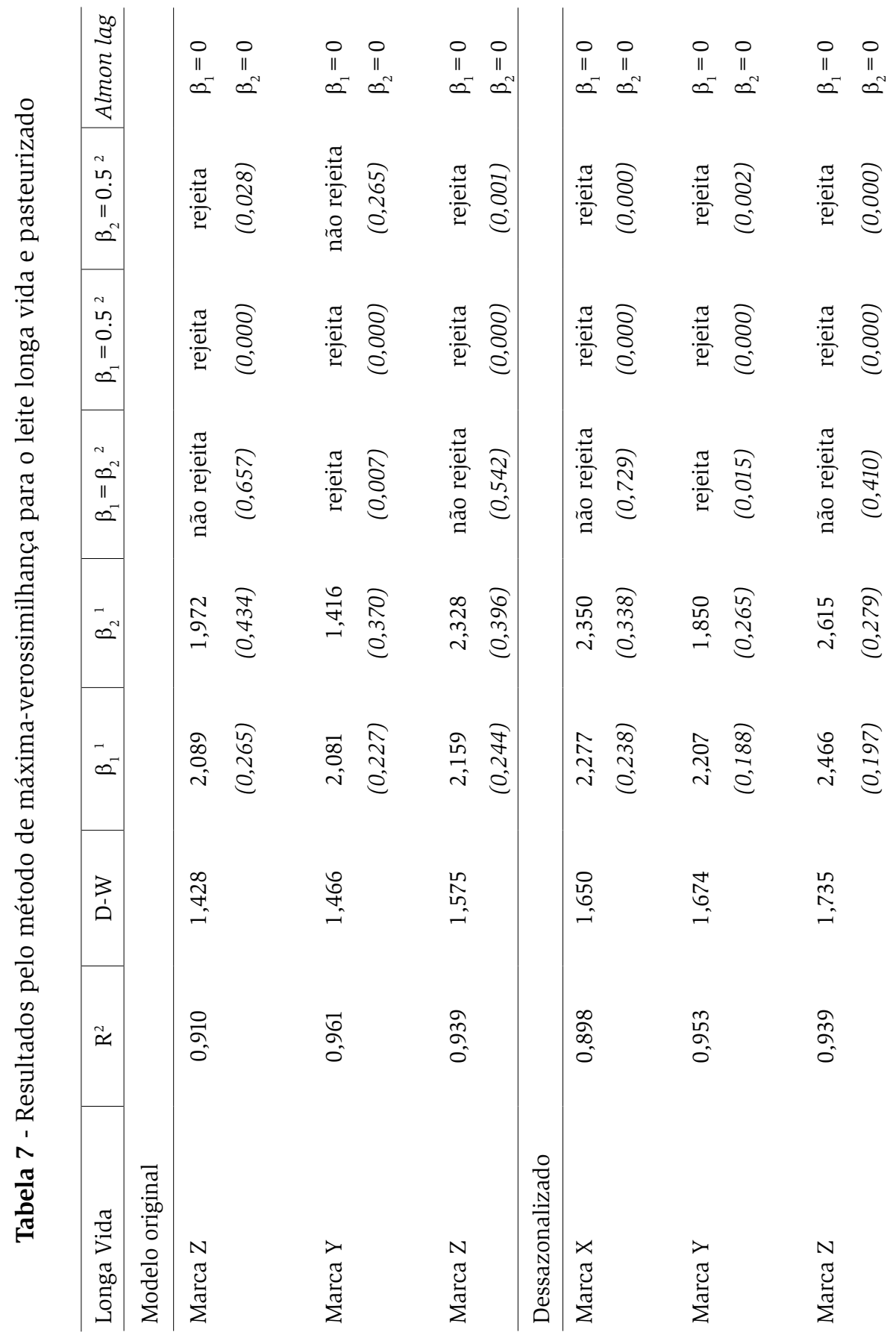




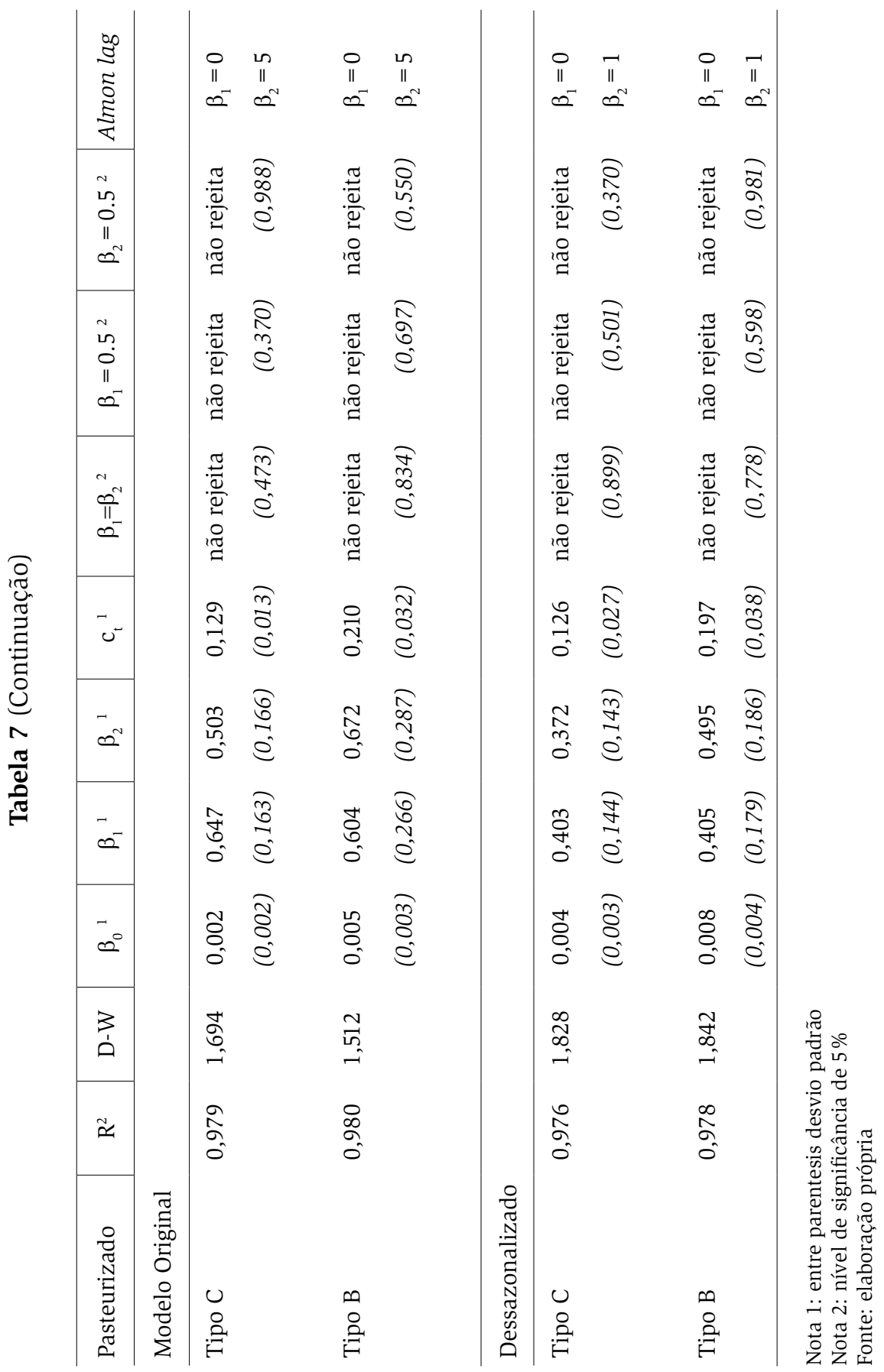


As diferenças nas características técnicas, particularmente pelo prazo de validade e necessidade de distribuição a frio, modificam a concorrência entre laticínios e o modo que as alterações de preços fluem pela cadeia produtiva. Na distribuição, a redução da freqüência de compras permitiu a consumidores a utilização de canais de distribuição que implicassem maior custo de deslocamento, fazendo com que as vendas migrassem de padarias para supermercados. Na indústria, o leite longa vida teve como efeito o alargamento das fronteiras dos mercados, com a incorporação de um maior número de produtores em um mesmo espaço de concorrência.

No caso do mercado de leite fluido em São Paulo, foram encontrados dois resultados diferentes. Para o leite longa vida, o padrão de concorrência é mais próximo do modelo competitivo. A partir dos resultados do teste, não foi encontrada nenhuma evidência de poder de mercado em relação à assimetria de transmissão de aumentos e decréscimos de preços, tampouco em relação à velocidade de transmissão. O maior indício de imperfeição de mercado decorre das evidências de utilização de markup de percentual fixo. Esse resultado é convergente com as práticas de precificação de grandes supermercados - a distribuição modal do leite longa vida -, que cobram um percentual fixo de serviço de venda sobre o preço de aquisição de cada produto. Apesar da oferta pulverizada em São Paulo, com 36 marcas oferecidas segundo dados da POF de 1998/99 (Margarido; Martins, 2005), a magnitude da transmissão de preços indica que indústria e varejo apresentam algum poder de mercado.

Em relação ao leite pasteurizado, os resultados apontaram para um mercado pouco competitivo, o que provavelmente decorre da sua menor área de abrangência. O resultado de não-rejeição da hipótese de monopólio no teste empírico encontra justificativa mais pelos limites geográficos da distribuição de um produto perecível do que por características estruturais, como barreiras à entrada. Embora a precificação seja consistente com o comportamento monopolista, as características da produção de leite pasteurizado não indicam que há rendas elevadas, sustentáveis por barreiras à entrada. Esse resultado de imperfeições na transmissão de preços deve estar atrelado à menor liquidez de um mercado baseado em produto perecível e 
que apresenta problemas de organização e fluxo de informação. De qualquer forma, é digno de nota que a transmissão de preços na cadeia de leite pasteurizado seja consistente com a estrutura de mercado monopolista.

Os resultados permitem algumas inferências para análises setoriais e de políticas públicas voltadas à produção leiteira. A transformação no mercado de leite observada nos últimos 15 anos trouxe maior concorrência nos segmentos de indústria e distribuição, bem como maior velocidade de transmissão de preços ao longo da cadeia produtiva. Sem levar em consideração eventuais conseqüências do maior consumo de longa vida para a população em geral, pode-se afirmar que o SAL passou a funcionar de um modo mais próximo ao esperado em ambientes de maior concorrência. Entretanto, o modo de precificação com markups com percentual fixo indica que indústria e distribuição gozam de algum poder de mercado e que variações de custo da matéria-prima são repassadas mais que proporcionalmente, em termos absolutos, ao consumidor final.

Segundo produtores, indústria e varejo não estariam repassando as quedas dos preços pagos ao produtor para o consumidor. Não foi encontrado qualquer indício empírico para esta afirmação no mercado de leite longa vida, que representa aproximadamente $80 \%$ do mercado. Pelo contrário, movimentos de aumentos e diminuições de preços apresentaram a mesma defasagem e a mesma magnitude. O que provavelmente ocasiona essa relação desigual é que indústria e varejo apresentam suficiente poder de mercado para fazer uso de estratégias de precificação com markup com percentual fixo.

A principal limitação dessa pesquisa é restringir-se à análise de transmissão de preços, o que muitas vezes é insuficiente para concluir sobre o padrão de concorrência e se houve variação significativa de diferenciação de produtos ou imperfeições de mercado decorrentes de problemas de informação e custos de transação. Para tanto, seria desejável replicar esta análise em diferentes mercados relevantes e que apresentem graus de concentração de mercado distintos. Assim, seria possível avaliar se as estratégias de precificação decorrem, de fato, do padrão de concorrência ou de outros tipos de imperfeições de mercado. 


\section{Referências bibliográficas}

AGUIAR, Danilo R. D.; SANTANA, Josana A. Asymmetry in farm to retail price transmission: evidence from Brazil. Agribusiness, New York, vol. 18 (1), p. 37-48, 2002.

ALVES, Daniela Rodrigues. Industrialização e comercialização do leite de consumo no Brasil. In: MADALENA, Fernando Enrique; MATOS, Leovegildo Lopes de; HOLANDA JR., Evandro Vasconcelos. Produção de leite e sociedade: uma análise crítica da cadeia do leite no Brasil. Belo Horizonte, FEP-MVZ Editora, 2001, cap. 4, p. 75-83.

AZEVEDO, Paulo Furquim de; CHADDAD, Fábio Ribas; FARINA, Elizabeth Maria Mercier Querido. The Food Industry in Brazil and in the U.S.: the impacts of FTAA on trade and investments. Buenos AiresArgentina: IDB-INTAL, 2004. (Working Paper).

BARROS, Geraldo Sant'Ana de Camargo et al.. Sistema agroindustrial do leite no Brasil. Brasília, DF: Embrapa Informação Tecnológica, 2001. $170 \mathrm{p}$.

BARROS, Geraldo Sant'Ana de Camargo et al.. Mudanças estruturais na cadeia do leite: reflexo sobre os preços. Revista de Política Agrícola, Brasília, DF, ano 13, n. 3, p. 13-26, Jul./Ago./Set. 2004.

CAPPS JR., Oral; SHERWELL, Pablo. Spatial assymetry in farmretail price transmission associated with fluid milk products. 2005 . In: American Agricultural Economics Association Annual Meeting, Providence, Rhode Island, 2005. Não publicado.

CARMAN, Hoy F.; SEXTON, Richard J. Supermarket fluid milk pricing practices in the Western United States. Agribusiness, New York, vol. 21, p. 509-530, Fall 2005.

CEPEA (Centro de Estudos Avançados em Economia Aplicada) - ESALQ/ USP, Piracicaba. Base de dados: série de preços médios nominais do leite C recebidos pelo produtor. Disponível em: < http://www.cepea. esalq.usp.br/leite/page.php?id_page=155 > . Acesso em: 17 jan. 2006.

ENDERS, Walter. Applied Econometric Time Series. $2^{\mathrm{a}}$ ed. New Jersey: John Wiley and Sons, Inc., 2004. 460 p. 
EMBRAPA GADO DE LEITE. Empresa Brasileira de Pesquisa Agropecuária. Brasília, DF, Base de dados: Estatísticas do leite. Disponível em:<http://www.cnpgl.embrapa.br/>. Acesso em: $29 \mathrm{dez}$. 2005.

EVIEWS 3, Quantitative Micro Software. User's Guide. $2^{\text {nd }}$ ed. Irvine, California: QMS, 1998. 656 p.

FRIGON, Mathieu; DOYON, Maurice; ROMAIN, Robert. Asymetry in farm-retail price transmission in the northeastern fluid milk market. Food Marketing Policy Center, Research Report, No. 45, University of Connecticut, May 1999.

FUNDAÇÃO INSTITUTO DE PESQUISAS ECONÔMICAS (FIPE), São Paulo. Base de dados: preços nominais do leite em São Paulo. Disponível em: disquete. Base fev. 2006.

HALL, R. L.; HITCH, C. Price theory and business behavior. Oxford economic papers, n. 2, p. 12-45. May 1939.

HEIEN, Dale M. Markup pricing in a dynamic model of the food industry. American Journal of Agricultural Economics, Ames, IA, vol. 62, 10-18, 1980.

HOUCK, James P. An approach to specifying and estimating nonreversible functions. American Journal of Agricultural Economics, Ames, IA, vol. 59, p. 570-572, 1977.

JANK, Marcos Sawaya; GALAN, Valter Bertini (1998). Competitividade do Sistema Agroindustrial do Leite. In:___ Competitividade no Agribusiness Brasileiro. São Paulo: Pensa, USP, Julho 1998. Disponível em: < http://www.pensa.org.br/ > . Acesso em: 23 jun. 2005.

MARGARIDO, Mario Antônio; MARTINS, Vagner Azarias. Participação de mercado e consumo de leite longa vida na cidade de São Paulo. Milkpoint, 10 nov. 2005. Disponível em < http://www.milkpoint.com. $\mathrm{br} />$. Acesso em 11.11.2005.

MARTINS, Marcelo Costa. Competitividade da cadeia produtiva do leite no Brasil. Revista de Política Agrícola, Brasília, DF, ano 13, n. 3 , p. 38-51, Jul./Ago./Set. 2004. 
MOTTA, Massimo. Competition Policy: theory and practice. Cambridge, UK: Cambridge University Press, 2004. 616 p.

NEVES, Marcos Fava; CONSOLI, Matheus Alberto (Coord.). Mapeamento e quantificação da cadeia do leite. In: Workshop do sistema agroindustrial citrícola, Programa de Estudos dos Negócios do Sistema Agroindustrial (PENSA), outubro 2005, Ribeirão Preto. Disponível em: < http://www.pensa.org.br/ > . Acesso em: 10 fev. 2006.

NO, Sung Chul; ZAPATA, Hector O.; SALASSI, Michael E.; GAUTHIER, Wayne M. (2004). Asymmetry in Farm-Milled Rice Price Transmission in the Major Rice Producing States in the U.S.. Journal of American Academy of Business, Cambridge, Mar 2004, 4, pp. 460-463.

PARROT, Scott D.; EASTWOOD, David B.; BROOKER, John R. (2001). Testing for symmetry in price transmission: an extension of the shiller lag structure with an application to fresh tomatoes. Journal of Agribusiness, Georgia, vol. 19, p. 35-49, spring 2001.

PICCHETTI, Paulo. Considerações sobre a escolha do método de dessazonalização de uma série. Informações Fundação Instituto de Pesquisas Econômicas (FIPE), São Paulo, p. 13-15, julho 2003.

SHY, Oz. Industrial Organization: theory and applications. Paperback edition. Cambridge, MA: The MIT Press, 1996. 488 p.

VARIAN, Hal R. Microeconomia: princípios básicos. $4^{\mathrm{a}}$ ed. Rio de Janeiro: Editora Campus, 1999. 740 p.

VASCONCELLOS, Marco Antonio Sandoval; ALVES, Denisard (Coord.). Manual de Econometria: nível intermediário. São Paulo: Editora Atlas, 2000.

WOOLDRIDGE, Jeffrey M. Introductory Econometrics: a modern approach. $2^{\text {nd }}$ ed. Mason, Ohio: South-Western, 2003. 863 p. 